\title{
A Regulação Responsiva das Telecomunicações: Novos horizontes para o controle de obrigações pela Anatel
} Responsive Regulation in Telecommunications: New horizons for the Anatel's Enforcement

Submitted: $17 / 12 / 2016$ Revised: $14 / 01 / 2017$ Accepted: $16 / 03 / 2017$
João Marcelo Azevedo Marques Mello da Silva*

\begin{abstract}
Resumo
Propósito - O propósito deste trabalho foi avaliar a aplicação de estratégias características de regulação responsiva na discussão do novo modelo de telecomunicaçõ es brasileiro.

Metodologia/abordagem/design - Valendo-se da teoria da regulação responsiva de Ayres e Braithwaite, foram avaliadas as revisões do modelo de gestão de qualidade e de acompanhamento e controle em andamento na Anatel.
\end{abstract}

Resultados - A pesquisa demonstrou que a Agência vem utilizando, ainda que de maneira embrionária, técnicas de regulação responsiva nos novos instrumentos que serão aplicadas no novo modelo de prestação de serviços de telecomunicações brasileiro.

Implicações práticas - A análise presente neste trabalho pode subsidiar as discussões em andamento e aprimorar a atuação regulatória da Agência.

Originalidade/relevância do texto - A presente pesquisa indica que a Anatel vem buscando se valer deliberadamente de estratégias de regulação responsiva na sua atuação.

Palavras-chave: telecomunicações, regulação responsiva, evolução, enforcement.

\begin{abstract}
Purpose - The purpose of this article is to assess the use of responsive regulation strategies in the debate about the new Brazilian telecommunications framework.

Methodology/approach/design - The Responsive Regulation Theory proposed by Ayres and Braithwaite is used as lenses to evaluate Anatel's quality management and command and control model.
\end{abstract}

Findings - The research showed that Anatel is using, even though in an embryonic manner, responsive regulation techniques in the new regulation that will be applied in the new Brazilian telecommunications framework.

Practical implications - The result of this work can be used to improve the regulation by Anatel.

Originality/value - The research showed that Anatel tends do use responsive regulation strategy in a regular manner.

Keywords: telecommunications, responsive regulation, evolution, enforcement.

\footnotetext{
*Mestre em Engenharia Elétrica pela Université Laval em Québec, Canadá. Graduado em Engenharia Elétrica e Direito pela Universidade de São Paulo. Atua como Especialista em Regulação de Serviços Públicos de Telecomunicações da Agência Nacional de Telecomunicações (ANATEL) desde 2005. E-mail: joaomarcelomello@ gmail.com.
} 


\section{Introdução}

O objetivo deste trabalho é apresentar aspectos de regulação responsiva que estão sendo considerados na reformulação do modelo de prestação dos serviços de telecomunicações no Brasil. Baseando-se na teoria apresentada por Ayres e Braithwaite (1992) e naquelas que dela se originaram, buscar-se-á identificar a utilização de ferramentas compatíveis com a pirâmide regulatória, pilar da referida teoria, nos diferentes instrumentos que darão uma nova face à regulação do setor.

O emprego pela Agência de técnicas modernas e alternativas de regulação, que não consistem simplesmente na aplicação sanções em caso de descumprimento de regras, tais como a regulação responsiva, é de relevante importância, pois demonstra o amadurecimento da instituição e dos métodos empregados para obter os resultados obtidos. Além disso, a consideração de outros inputs no processo de criação, definição e aplicação de regras revela a procura pela regulação de alta qualidade, mais compatível com os anseios da sociedade e mais aderente à estrutura do mercado de telecomunicações. Neste sentido, a regulação deve expandir sua área de atuação, buscando, sempre que possível, apurar as diferentes motivações e complexidades inerentes ao cenário atual e compreender a estrutura do setor regulado, de forma a atingir o objetivo de agir da maneira mais apropriada frente às diversas situações. Tal necessidade é ainda mais necessária em situações de mudança, como aquelas pelas quais o mercado regulado está passando.

O presente trabalho é dividido em três partes. A primeiras delas apresenta os principais pressupostos da Teoria da Regulação Responsiva, as críticas a ela direcionadas e as alternativas que emergiram posteriormente. A segunda parte traz uma breve contextualização do atual cenário de mudanças na regulação dos serviços de telecomunicações, que envolve a própria reformulação do modelo de prestação, bem como dos demais instrumentos regulatórios relacionados. Por fim, serão analisadas as estratégias de regulação responsiva empregadas na revisão dos modelos de gestão da qualidade do serviço e do acompanhamento e controle das obrigações das entidades reguladas.

\section{A Teoria da Regulação Responsiva}

A teoria da Regulação Responsiva foi concebida da necessidade de se superar o debate entre aqueles que entendem ser necessária uma forte regulação estatal da atividade econômica e os defensores da desregulação. Apresentada no início dos anos 90 do século passado por Ayres e Braithwaite (AYRES e BRAITHWAITE, 1992), tal teoria ofereceu desenhos regulatórios flexíveis e 
adaptativos, que estabelecem sinergia entre punição e persuasão, possibilitando o estabelecimento de formas de regulação compatíveis com a realidade vislumbrada e os objetivos buscados. Para tanto, ela preconiza a necessidade de se conhecer a fundo a estrutura do mercado regulado, suas normas internas e as motivações dos atores.

Umas das ideias originais e centrais da Regulação Responsiva é a chamada pirâmide regulatória, que prevê medidas crescentes de intervenção estatal, a depender do comportamento dos regulados. De acordo com o modelo criado, a autorregulação é a técnica inicial a ser empregada, aplicável na base da pirâmide, quando as condutas estão em conformidade e ocorre pouca ou nenhuma ingerência governamental. Na hipótese de serem identificadas irregularidades, sem a devida correção pelos infratores, a pirâmide é escalada, passando-se por medidas e estágios intermediários, até se chegar a punições extremas, quando as irregularidades são persistentes, podendo resultar altos valores de multa ou mesmo a incapacitação da empresa regulada.

Os adeptos de tal teoria defendem que a simples possibilidade de se escalar as medidas regulatórias previstas na pirâmide já seria capaz de impulsionar as empresas reguladas a adotarem todas as medidas para que isso não aconteça, de modo a se evitar um aumento da intervenção estatal na conduta da empresa. Além de mencionar diversos estudos empíricos sobre o tema, que avaliaram, por exemplo, o mercado de abrigos para idosos na Austrália, os autores apresentam análise econômica aprofundada que envolve a teoria dos jogos e auxilia na fundamentação de seu ponto de vista (AYRES et al. 1992. p. 61-70).

Outra característica de tal teoria é inexistência de qualquer tipo de definição ou prescrição da medida regulatória a ser tomada em determinada situação. A melhor estratégia dependerá do contexto e da própria cultura regulatória, baseando-se também no comportamento histórico dos regulados.

Assim, diante da necessidade de se estabelecer estratégias regulatórias que permitam a obtenção de resultados efetivos, no sentido de reduzir a incidência de prejuízos sociais, e eficientes, com o menor custo aos reguladores e regulados, a Regulação Responsiva busca justamente identificar e disponibilizar aos órgãos governamentais as melhores técnicas para cada situação particular. Para tanto, devem ser desenhados e utilizados os comandos legais disponíveis e apropriados, que normalmente demandam a inclusão de técnicas de enforcement, pois são raras as regras que atinjam seus objetivos sem o devido enforcement (GUNNINGHAM, 2010, p. 120). 
Na definição de tais técnicas de enforcement, os órgãos reguladores podem escolher entre dois grandes gêneros de técnicas de enforcement, quais sejam, a dissuasão ${ }^{1}$ e a persuasão ${ }^{2}$.

A primeira, largamente utilizada na regulação brasileira, caracteriza-se por ser uma técnica de enforcement de confronto, que se utiliza de punições todas as vezes que são identificadas infrações às regras. Além de ser acusatória e envolver partes adversárias, grande parte da energia é canalizada para detectar violações, estabelecer a culpa e penalizar os ofensores pelo comportamento irregular. Utiliza-se nesse caso a premissa de que os regulados são atores racionais, que somente respondem a incentivos econômicos, devendo ser aplicadas punições severas para dissuadi-los da prática de violações futuras.

Por outro lado, a outra técnica, conhecida por persuasão ou aconselhamento, enfatiza a cooperação e a conciliação, ao invés do confronto e da coerção. Ela busca prevenir prejuízos, antes mesmo de tentar punir o mau comportamento, tendo como foco o atingimento do objetivo buscado pela norma e não simplesmente punir os infratores após o seu descumprimento. Ao contrário da estratégia de dissuasão, é rara a utilização de processos legais, sendo ela caracterizada principalmente pela negociação. Não obstante, permanece a ameaça de punição, como um pano de fundo, sendo utilizada somente quando a todo o resto falha e o regulado continua a não cooperar após a conclusão do processo negocial.

Como mencionado por Ayres e Braithwaite (1992, p. 19), a punição é cara e persuasão é barata. Consequentemente, a utilização de estratégias majoritariamente punitivas termina desperdiçando recursos em litígios que poderiam ser mais bens gastos em monitoramento e persuasão. Nas palavras dos autores supracitados, tomando como exemplo fictício a fiscalização de minas, " $A$ highly punitive mining inspectorate will spend more time in court than in mines" (AYRES, et al. p. 20).

Ambas técnicas - dissuasão e persuasão - possuem pontos positivos e negativos e evidências empíricas que reforçam sua aplicabilidade ${ }^{3}$. Uma estratégia unicamente baseada em técnicas de persuasão será explorada por atores motivados unicamente por razões econômicas, enquanto que estratégias fundamentadas somente em dissuasão poderão reduzir a boa vontade dos

${ }^{1}$ Comumente, utiliza-se o termo "deterrence" para designar a técnica regulatória de persuasão. O Miriam Webster Dictionary traz a seguinte definição: "the inhibition of criminal behavior by fear of punishment". As grafias em inglês e em português serão utilizadas indiscriminadamente neste trabalho.

${ }^{2} \mathrm{O}$ termo usualmente utilizado em inglês para persuasão é "persuasion".

${ }^{3}$ Em Gunningham (2010, p. 122-125), há uma apresentação de alguns estudos conduzidos por diversos autores que demonstram o potencial de cada uma das estratégias. 
regulados imbuídos de motivações que não sejam unicamente econômicas, como um senso de responsabilidade de seus executivos.

Como já mencionado, a regulação responsiva sustenta a aplicação de uma composição de estratégias de dissuasão e persuasão, permitindo, assim, que os ofensores sejam dissuadidos a prosseguir praticando irregularidades, encorajando os atores virtuosos a cumprir as regras voluntariamente e, em evoluções posteriores da teoria, recompensando os regulados que se superam e vão além das normas previamente estabelecidas.

A grande dificuldade é definir qual das técnicas aplicar, uma vez que tal escolha demanda a identificação da motivação dos regulados. Justamente para tentar superar este obstáculo foi concebida a pirâmide regulatória que busca explanar, de maneira simples e de fácil compreensão, que tipo de ação deve ser tomada pelos reguladores em cada situação. O próprio nome da teoria já indica a necessidade de os reguladores serem responsivos às ações dos regulados, permitindo a adoção das medidas corretas e que propiciem efetividade à regulação.

Na pirâmide regulatória original, criada por Ayres e Braithwaite em 1992, os reguladores devem sempre iniciar pela técnica regulatória localizada na base, assumindo a virtude dos regulados. Assim, por exemplo, se for identificado o cometimento de uma infração por um ator, ele será advertido por tal fato pelo órgão regulador, sem maiores consequências. Se esta primeira resposta regulatória não surtir o efeito desejado, a pirâmide será escalada e outras técnicas mais intervencionistas serão aplicadas, ainda sem grandes efeitos. A partir do momento em que se verifique que as medidas iniciais mais brandas não estão surtindo os efeitos desejados, a pirâmide será escalada até que sejam aplicadas medidas regulatórias cada vez mais intervencionistas e de caráter punitivo crescente, podendo atingir até penas que incapacitem o ator a atuar no mercado regulado. Do mesmo modo, se for constatado que as medidas tomadas resultaram em mudança no comportamento do regulado e ele deixou de praticar as condutas indesejadas, ocorrerá o caminho oposto, ou seja, as próximas medidas tomadas terão caráter punitivo e intervencionista inferior àquelas utilizadas previamente.

É criado, portanto, um modelo dinâmico, no qual o comportamento dos regulados vai determinar se uma resposta mais ou menos intervencionista e punitiva é necessária. De acordo com os defensores desta teoria, a atuação regulatória nestes termos força os infratores a cumprirem as regras, ao mesmo tempo em que motiva os atores virtuosos a continuar agindo da maneira correta. Em outras palavras, o desenho regulatório em questão traz à tona os pontos fortes das formas de regulação existentes, de tal maneira que eles compensam os pontos fracos das outras (BRAITHWAITE, 2011. p. 485) e possibilitam aplicar uma ou outra técnica mais adequada ao comportamento verificado (KOLIEB, 2015. p.139). 
Além disso, através de interações entre os regulados e reguladores, nas diferentes camadas da pirâmide, torna-se possível apurar as motivações das empresas, identificar quais delas são exemplares ou líderes, relutantes em cumprir as regras, reincidentes ou incompetentes e, o mais importante, permite-se elaborar uma resposta regulatória no mesmo tom (GUNNINGHAM, 2010. p. 126).

A representação da pirâmide regulatória, conforme exemplo que Ayres e Braithwaite (1992, p. 35) trazem em sua obra inaugural da teoria e reproduzida na figura 1, traz a ideia de que a maioria das ações ocorrem na base da pirâmide, que possui uma área maior, onde são utilizadas medidas de persuasão para se obter a conformidade com as normas vigentes. A partir do momento em que se apure que tais medidas não estão sendo suficientes para modificar o comportamento dos regulados, o nível de intervenção aumenta, porém a sua aplicação será menos frequente. Níveis ainda superiores podem ser utilizados, com uma frequência menor, até que se atinja o seu ápice, que possui uma área reduzida, onde se prevê uma medida rara e extrema, que pode até incapacitar o agente.

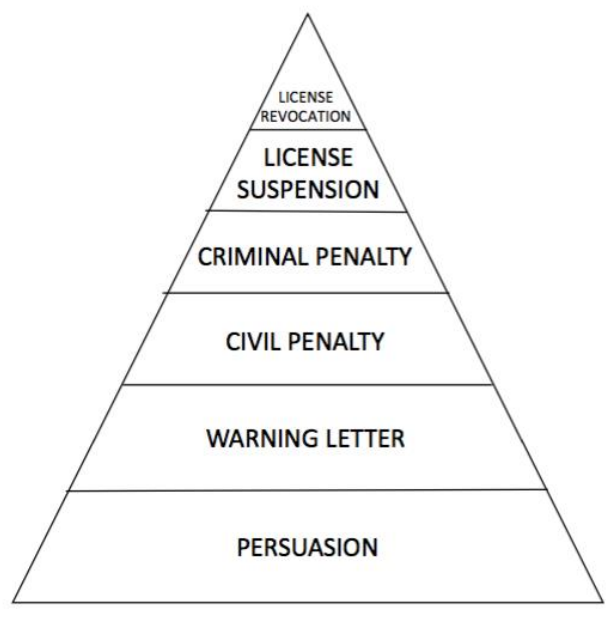

Figura 1 - Pirâmide Regulatória (AYRES e BRAITHWAITE, 1992 - pg. 35)

Como mencionado pelos autores, a pirâmide fictícia, acima reproduzida, tem possível aplicação na regulação de casas de repouso, porém seriam incompatíveis com o mercado bancário, por exemplo. Eles destacam, ainda, que o foco da discussão não é o conteúdo da pirâmide de enforcement, mas sua forma, e afirmam que diferentes tipos de sancionamento são apropriados para diferentes arenas regulatórias (AYRES et al, 1992. p. 36), ou seja, as ações regulatórias devem ser elaboradas de acordo com a estrutura do mercado regulado e os atores neles presentes. 
Deste modo, diante da inexistência de métodos ótimos regulatórios, aplicáveis em toda e qualquer situação, a pirâmide regulatória tenta criar uma estrutura dinâmica, na qual podem ser utilizadas diferentes técnicas, porém com foco no espaço mais flexível existente em sua base. Com isso, busca-se concentrar os esforços dos reguladores em opções mais baratas e colaborativas, deixando as demais opções, caras, demoradas e complexas para serem utilizadas em situações extremas, localizadas no topo da pirâmide.

Além disso, diante da fluidez do comportamento dos regulados e dos reguladores, a pirâmide busca modular respostas apropriadas para cada um deles, em um dado momento. Como mencionado por Ayres e Braithwaite, a maioria dos regulados são contraditórios e comprometidos, a depender do momento e do contexto, com a busca de valores econômicos, o cumprimento da lei ou a responsabilidade social do negócio. Do mesmo modo, os agentes reguladores também possuem diferentes personalidades e os desastres regulatórios ocorrem justamente quando a personalidade do regulador exigente, não profissional e confusa se encontra com a personalidade irresponsável e na busca do lucro a todo custo do empresário (AYRES et al., 1992. p. 36). A utilização da pirâmide regulatória, prevendo as medidas persuasivas em sua base, busca exatamente evitar tais desastres e possibilitar que as personalidades cooperativas se sobressaiam e que o cumprimento das regras seja realizado da maneira menos custosa para os envolvidos. Qualquer indício de falta de cooperação por parte dos regulados possibilita a identificação de motivações diversas e dispara as medidas mais apropriadas para aquela situação.

Em resumo, portanto, a regulação responsiva se diferencia das demais estratégias de regulação em relação ao que dispara as respostas regulatórias e qual esta resposta será (AYRES et al., 1992. p. 5), permitindo a utilização das técnicas de enforcement mais adequadas a cada caso, aumentando, assim, a probabilidade do atingimento dos objetivos elencados pelo Estado.

As ideias e conceitos da Regulação Responsiva já foram e continuam sendo aplicados em entidades governamentais e organismos internacionais (KOLIEB, 2015, p. 142; BRAITHWAITE, 2011, p. 482). Ainda de maneira embrionária, percebe-se o início de discussões a respeito de técnicas responsivas pelas agências reguladoras brasileiras, a exemplo do que ocorre na ANEEL, no âmbito do Projeto de Fiscalização Estratégica ${ }^{4}$, e na Anatel (JESUS, 2015 e ARANHA, 2016).

Apesar disso, são diversas as críticas e as propostas de aprimoramentos à teoria, de modo que um dos autores propôs alguns aperfeiçoamentos posteriores,

\footnotetext{
${ }^{4}$ ANEEL - Fiscalização Estratégica: A nova metodologia de fiscalização dos serviços de distribuição e transmissão de energia elétrica. Disponível em http://www2.aneel.gov.br/arquivos/PDF/ficalizacao estrategica-evento-03-03-2016.pdf.
} Acesso em 10/12/2016. 
introduzindo novas ideias relevantes sobre o tema em obras mais recentes (BRAITHWAITE, 2007 e 2011). O presente trabalho não tem como objetivo analisar estes novos conceitos, tampouco fazer uma análise exaustiva das críticas recebidas. Não obstante serão revisitados os principais pontos controversos compilados em duas obras de estudiosos do tema (GUNNINGHAM, 2011; BALDWIN, CAVE E LODGE, 2012, p. 259-279), assim como um trabalho mais recente que trata do tema (KOLIEB, 2015).

Dentre as críticas apontadas, destacam-se aquelas relacionadas aos aspectos operacionais envolvidos com a subida ou descida das camadas da pirâmide. Questiona-se, por exemplo, a adequação da escalada passo a passo em situações que envolvem riscos catastróficos, tais como acidentes nucleares, onde a utilização de técnicas de persuasão, localizadas na base da pirâmide, pode não ser a estratégia mais indicada. De maneira semelhante, quando já se possui uma caracterização muito clara do comportamento dos regulados e dos papéis que eles desempenham, o mais apropriado seria partir diretamente para técnicas de enforcement mais duras, situadas em níveis superiores da pirâmide regulatória, sem percorrer os níveis inferiores. Os efeitos que as subidas e descidas das respostas regulatórias teriam na relação entre reguladores e regulados também são alvo de questionamentos, uma vez que elas podem gerar perda de confiança entre as partes, trazendo prejuízos diretos à aplicação de medidas menos punitivas.

Outra categoria de deficiências apontadas diz respeito ao fluxo de informações entre reguladores e regulados, tão necessário para que a regulação responsiva tenha sucesso. Assim, caso não exista harmonização entre os objetivos regulatórios e as normas empresariais ou caso as mensagens entre reguladores e regulados não tenham um fluxo efetivo, causado, por exemplo, por interações pouco frequentes ou ruidosas, certamente haverá um prejuízo à atuação por meio da regulação responsiva, tornando-a até inviável em determinadas situações.

Existem também dúvidas relacionadas à legalidade da abordagem responsiva, isso porque normalmente as normas determinam que a infração por determinada conduta implica uma certa punição previamente estipulada. Logo, qualquer tipo de tratamento diverso pode ser considerado ilegal e inviabilizar a utilização das medidas alternativas. De maneira semelhante, a utilização de respostas individualizadas e adaptadas para cada ator carrega um elevado nível de discricionariedade, o que pode ser interpretado como atuação pouco transparente, parcial e benéfica a determinados atores em detrimento de outros. Por fim, nem sempre estão disponíveis as medidas ou sanções necessárias para que a escalada da pirâmide seja aplicável, já que a regulação responsiva requer um número relevante para que seus efeitos sejam percebidos.

Como solução a tais questionamentos, são apresentadas alternativas e evoluções à regulação responsiva, que vão desde pequenos ajustes que 
possibilitariam contornar as deficiências detectadas, tais como a Smart Regulation (GUNNINGHAM e GRABOSKY, 1998) e o Diamante Regulatório (KOLIEB, 2015), até uma significativa reformulação da ideia, como a Problem-centered Regulation (SPARROW, 2000) ou a Meta-Regulation (PARKER, 2002). Não obstante, todas as soluções apresentadas guardam profunda correspondência com a teoria original de 1992, e buscam levá-la além, o que reforça o seu potencial e aplicabilidade aos casos concretos.

Dentre as propostas apresentadas, destacam-se a Really Responsive Regulation (BALDWIN e BLACK, 2008), a Problem-centered Regulation e o recente trabalho de Kolieb (2015) que introduziu o conceito de Diamante Regulatório.

A primeira teoria - Really Responsive Regulation ou Regulação Realmente Responsiva - apresenta um framework que aborda a regulação responsiva de uma maneira mais geral e endereça uma série de questões não abordadas pela teoria original.

Em essência, esta teoria apresenta duas principais mensagens. A primeira delas é que os reguladores, quando desenharem, aplicarem e desenvolverem os sistemas regulatórios, devem adaptar suas estratégias a algo a mais que o comportamento dos regulados. De acordo com os autores, os reguladores:

"devem ser atentos e responsivos a quatro fatores principais: 0 comportamento, atitudes e cultura dos atores regulados; 0 arranjo institucional do regime regulatório; as interações entre as diferentes lógicas de ferramentas e estratégias regulatórias; o desempenho do próprio regime com o passar do tempo; e, finalmente, as mudanças em cada um desses elementos" ${ }^{\prime 5}$.

A segunda mensagem é no sentido de que:

"o desenho, o desenvolvimento e a operação regulatória deve levar em consideração a maneira com que os desafios regulatórios variam entre as principais tarefas que os reguladores devem praticar, tanto em respeito às empresas individuais, quanto no desenvolvimento de estratégias mais gerais, quais sejam: detecção de comportamento indesejáveis ou irregulares, resposta a estes comportamentos através do desenvolvimento de estratégias e ferramentas, imposição destas ferramentas e estratégias de fato, avaliação do sucesso ou estratégias, e modificação quando necessário"6.

A complexidade e diversidade das tarefas que são tratadas nesta teoria representam justamente o seu maior desafio, uma vez que a sua abordagem demanda requisitos de informação, de análise e de recursos que nem sempre

${ }^{5}$ Baldwin et al., 2012, p. 269 - tradução livre.

${ }^{6}$ Ibid p. 271-272 - tradução livre.

MELLO DA SILVA, J.M A. M. A Regulação Responsiva das Telecomunicações: Novos borizontes para o controle de obrigacões pela Anatel. Revista de Direito, Estado e Telecomunicações, Brasilia, v. 9, n. 1, p. 183208, maio de 2017. [DOI: https://doi.org/10.26512/lstr.v9i1.21519] 
podem ser obtidos. Não obstante, o framework que tal teoria apresenta é bastante interessante e pode ser utilizado para endereçar diversas questões regulatórias.

A Problem-centered Regulation, ou Regulação Baseada em Problemas, que pode ser considerada uma versão da Regulação Baseada em Risco (Riskbased Regulation $^{7}$ ), é uma teoria que posiciona a solução de problemas no centro da estratégia regulatória (BALDWIN, 2010.p.267). Ao contrário das teorias até aqui apresentadas, que se baseiam nos processos, ferramentas e instituições que podem ser utilizados, a Problem-centered Regulation primeiro elenca os principais problemas e depois decide quais as estratégias serão utilizadas para resolvê-lo. Além de colocar em destaque as tarefas que os reguladores devem executar em suas atividades, esta teoria possui relevante importância porque enfatiza a importância da avaliação de desempenho e desafios da mudança e concentra seus esforços nos resultados finais, ao invés de se limitar à avaliação do cumprimento das regras (compliance). Contudo, assim como as demais teorias até aqui apresentadas, ela possui fragilidades que se relacionam principalmente às dificuldades de implantação e a possível simplificação excessiva de problemas que podem se revelar mais complexos que inicialmente identificados.

Por fim, a última teoria a ser apresentada no presente trabalho é chamada de Diamante Regulatório, divulgada em artigo recente cujo título traz uma dimensão a mais à onipresente pergunta "Quando punir? Quando Persuadir". De acordo com o autor, a teoria da regulação responsiva falha ao concentrar suas ações somente na minimização dos prejuízos e na busca do cumprimento das regras pelos regulados, o que seria apenas uma das facetas da regulação. A fim de explorar todo o potencial, o autor defende que as técnicas regulatórias também podem ser utilizadas para se superar os padrões legais e atingir o que se chama de "beyond compliance", ou seja, o atingimento de patamares superiores àqueles que as normas estabelecem. Deste modo, ele adiciona a questão "Quando recompensar?" às duas perguntas anteriormente mencionadas, o que, eu seu entender poderia garantir uma melhoria contínua na atividade regulatória e promover os regulados virtuosos.

A principal inovação desta teoria é a incorporação de duas atividades regulatórias, quais sejam, a regulação de compliance, que são os mecanismos utilizados para garantir o cumprimento de certos padrões, e a regulação aspiracional, que são as técnicas empregadas para encorajar os regulados a atingirem níveis superiores aos padrões comportamentais mínimos estabelecidos.

Como afirmado pelo próprio autor, "the regulatory diamond is an evolutionary, not revolutionary proposal" (KOLIEB, 2015. p. 150). Na verdade,

\footnotetext{
${ }^{7}$ A Risk-based Regulation pode ser definida como o conjunto de técnicas por meio das quais se priorizam de ações regulatórias, de acordo com a avaliação dos riscos incidentes sobre os objetivos buscados. (BALDWIN et al., 2012. p. 281).
} 
o modelo foi construído sobre as bases do trabalho de Braithwaite e das demais teorias dele decorrentes, sendo aderente à responsividade e ao dinamismo que são centrais à teoria da regulação responsiva.

A figura 2 possibilita a visualização do modelo proposto que pode ser entendido como uma visualização alternativa e aprimorada da pirâmide regulatória.

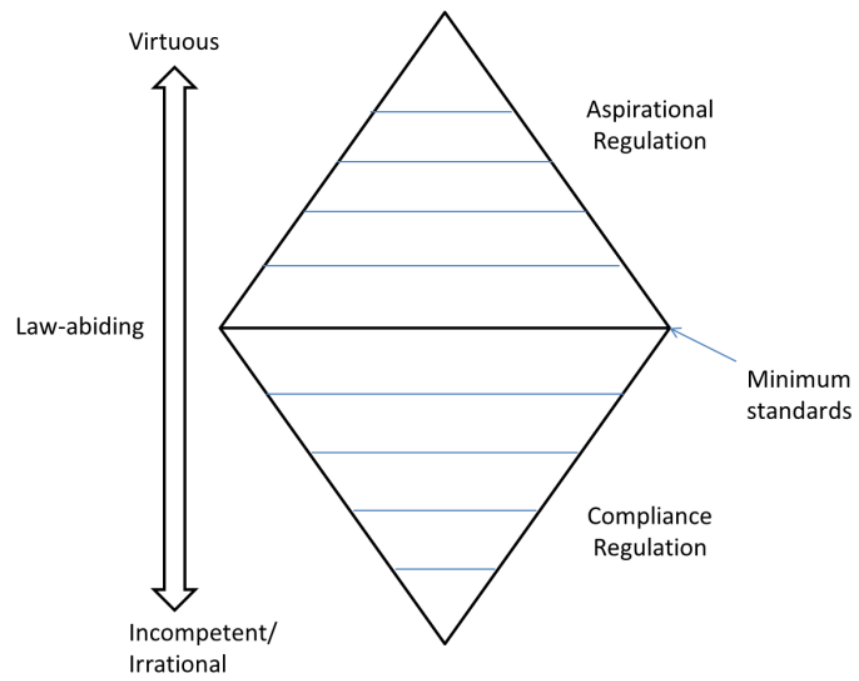

Figura 2 - Diamante regulatório (KOLIEB, 2015, p. 150)

O autor sustenta que a regulação deve incluir não só padrões mínimos comportamentais, mas também objetivos idealizados de conduta, bem como os mecanismos que busquem atingi-los. De acordo com a representação gráfica do diamante, os padrões mínimos comportamentais ("minimum standards") são a linha que reparte o diamante do meio; os mecanismos que conferem enforcement a estes padrões mínimos são representados pela regulação de conformidade ("compliance regulation") na porção inferior da figura; e os mecanismos que encorajam e incentivam os regulados a excederam os padrões mínimos e busquem atingir objetivos aspiracionais mais elevados são representados pela regulação aspiracional ("aspirational regulation") na porção superior da figura.

De maneira semelhante ao que ocorre com a regulação responsiva, à medida que se caminha em direção às duas extremidades do diamante, há uma redução da área, o que representa também uma diminuição da frequência de utilização dos mecanismos ali situados. Assim, quanto mais próximo à linha mediana, maior a frequência dos mecanismos. À medida que nos distanciamos 
dela, eles tornam-se mais raros, ao mesmo tempo em que eles passam a ser mais punitivos, por um lado, e mais compensadores, por outro.

Apesar das inovações trazidas por essa teoria, ela possui grande semelhança com as evoluções trazidas por um dos autores da própria Regulação Responsiva. Em trabalhos mais recentes, Braithwaite (2007 e 2011) introduziu o conceito de pyramid of supports, paralela à pirâmide de sanções original, que elenca uma série de recompensas que poderão ser dadas aos regulados se superarem os níveis estabelecidos. O próprio autor da teoria do Diamante Regulatório reconhece tal fato, todavia defende que a utilização de duas pirâmides separadas seria uma contradição, por trazer descontinuidade às técnicas empregadas.

Concluída a singela exposição sobre teoria que a suporta, passa-se a avaliação do uso das técnicas de Regulação Responsiva- e das que delas se originaram - nas propostas de modificações do arcabouço legal e regulamentar das telecomunicações em discussão.

\section{O modelo vigente de prestação dos serviços de telecomunicações e as modificações em discussão}

O atual modelo de prestação dos serviços de telecomunicações foi um dos produtos da chamada Reforma de Estado, empreendida pelo Governo Federal em meados da década de 90. Em processo de ampla reformulação do papel estatal nas atividades econômicas, entendeu-se, à época, que o Estado tinha se desviado de suas funções básicas e ampliado em demasia sua presença no setor produtivo, o que teria gerado como consequência uma deterioração dos serviços públicos (Presidência da República, 1995). Deste modo, em busca da estabilização e do crescimento sustentado da economia, foi elaborado um plano, que possuía como um dos aspectos centrais o fortalecimento do Estado, de modo a privilegiar sua ação reguladora em uma economia de mercado.

De fato, o quadro da prestação dos serviços públicos de telecomunicações que se apresentava no país naquele momento não era dos mais favoráveis aos seus usuários. Prestado sob o regime de monopólio Estatal, por meio das empresas do Sistema Telebrás ${ }^{8}$, e regido pelo Código Brasileiro de Telecomunicações, Lei ${ }^{\circ}$ 4.117/52, os notáveis avanços obtidos pelas empresas estatais até aquele momento não foram suficientes para se atender à demanda da sociedade, principalmente pela incapacidade de manutenção do nível de investimentos necessários. A

\footnotetext{
${ }^{8}$ Além das empresas integrantes do Sistema Telebrás, existiam quatro empresas independentes: CRT controlada pela Governo do Estado do Rio Grande do Sul, Sercomtel, controlada pelo Prefeitura de Londrina; a CETERP, controlada pela Prefeitura de Ribeirão Preto e a Cia de Telecomunicações do Brasil Central - CTBC, de capital privado.
} 
ausência de estatísticas confiáveis não nos permite quantificar exatamente a demanda reprimida que existia à época, porém, na Exposição de Motivos da Lei Geral de Telecomunicações (Exposição de Motivos n. 231/MC, 1996), os usuários potenciais foram estimados como sendo um número entre 18 e 25 milhões, enquanto que somente 14,5 milhões eram efetivamente atendidos.

Para superar este cenário, foram realizadas profundas reformas no setor de telecomunicações, que envolveram Emenda Constitucional para se extinguir o monopólio estatal nas telecomunicações, estabelecimento de um novo marco regulatório, principalmente por meio da LGT, e a privatização das empresas componentes do Sistema Telebrás ${ }^{9}$.

$\mathrm{O}$ modelo proposto à época, e ainda vigente, buscava colocar o usuário em primeiro lugar e possuía como principais pilares a competição e a universalização dos serviços. Para tanto, criou assimetrias regulatórias aplicáveis à prestação dos serviços pelos diferentes atores, que basicamente se dividiam entre os incumbents, que adquiriram as estatais no processo de privatização e já possuíam uma vantagem significativa na prestação do serviço fixo de telefonia, e os novos entrantes, que deveriam montar suas infraestruturas praticamente da estaca zero.

De acordo com a LGT, os primeiros passariam a prestar o serviço fixo de telefonia, cujo nome técnico é Serviço Telefônico Fixo Comutado (STFC), em regime público, com obrigações de universalização e continuidade e sujeitos a controle tarifário, enquanto que os últimos deveriam prestá-lo em regime privado, livres de tais obrigações ou controles ${ }^{10}$, além de ainda poderem prestar outros serviços neste mesmo regime, como os serviços de telefonia móvel.

A escolha pela prestação do STFC em regime público foi motivada por sua importância à época e pela indisponibilidade de qualquer outra alternativa que pudesse atender os anseios da sociedade de maneira satisfatória. A assunção das redes legadas das empresas privatizadas e o caráter de essencialidade de tal serviço justificavam o regime público de prestação e, consequentemente, a imposição de um maior número de obrigações às empresas operando neste regime, com o objetivo principal de atender o interesse público e expandir a prestação do serviço ao maior número de pessoas possível.

As obrigações impostas no Plano Geral de Metas para a Universalização (PGMU) $^{11}$, incluídas no Contrato de Concessão firmado pelas empresas, levaram o país a vivenciar, no final da década de 90 e no início dos anos 2000, uma

${ }^{9} \mathrm{O}$ detalhamento do processo de privatização, bem como de todos o histórico envolvido na transição, pode ser encontrado em Marques Neto e Coscione (2011).

${ }^{10}$ Para uma avaliação completa da diferenciação entre os regimes público e privado, vide Marques Neto e Coscione (2011, p. 54).

${ }^{11} \mathrm{O}$ primeiro PGMU foi aprovado pelo Decreto $\mathrm{n}^{\circ} 2.592$, de 15 de maio de 1998 . 
verdadeira revolução na prestação dos serviços de telecomunicações. O número de usuários de telefonia fixa, que na época da elaboração da LGT era de pouco mais de 14 milhões, ultrapassou a quantidade de 30 milhões, no ano de 2000 e continuou crescendo até atingir aproximadamente 45 milhões de usuários no ano de $2014^{12}$. Todos os municípios e localidades com mais de 300 habitantes foram atendidos, com instalações de terminais individuais ou coletivos (orelhões) por todo o país, o que possibilitou em tese o atendimento integral da população que desejasse se conectar.

Os dados acima dizem respeito somente à telefonia fixa. Se for levada em conta a quantidade de usuários do Serviço Móvel Pessoal (SMP), nome técnico do serviço de telefonia móvel, o número de usuários de telefones no país atingiu o total de 325,7 milhões no ano de 2014, número bastante expressivo e que supera a própria população brasileira.

Apesar dos números acima demonstrarem a assertividade da LGT e a evolução das telecomunicações por ela proporcionada, há uma demanda constante de mudanças que tem como motivação principal o profundo desenvolvimento das tecnologias de telecomunicações e informação desde o estabelecimento do marco regulatório. Vivenciou-se, neste período, o surgimento de alternativas de serviços mais interessantes que a tradicional telefonia fixa, tais como o Serviço Móvel Pessoal - SMP, que possuía em 2015 257,8 milhões de usuários e o Serviço de Comunicação Multimídia - SCM, por meio do qual é fornecido acesso fixo à internet, com 25,4 milhões de usuários no mesmo ano ${ }^{13}$. Além de tais serviços serem considerados, em determinados cenários, substitutos do STFC, eles são prestados por diversas empresas, em regime de acirrada competição.

Diante disso, existem aqueles que defendem que os dois pilares estabelecidos na LGT, universalização e competição, ainda que de maneira diversa da esperada, foram atendidas de maneira quase integral ${ }^{14}$.

Independentemente de entendimento a favor ou contrário a esta tese, é inegável que o cenário existente à época do estabelecimento do marco regulatório é substantivamente diverso do atual, seja devido à perda de essencialidade de STFC, seja pelo aparecimento de serviços alternativos mais interessantes que a simples telefonia fixa. Consequentemente, passou-se a se exigir modificações no

${ }^{12}$ Fonte Anatel - Relatórios Consolidados - Indicadores de 2012 a 2015. Disponível em http://www.anatel.gov.br/dados/2015-02-04-18-43-59. Acesso em 14/12/2016.

${ }^{13}$ Ibid.

${ }^{14}$ O Conselheiro Igor Vilas Boas de Freitas, em sua Análise $n^{\circ}$ 25/2016/GCIF, de 12/2/2016, assim expôs seu entendimento sobre a matéria: "4.2.67. (...) Assim, como fundamento para propor a reformulação da aplicação do regime público para o STFC, é que busco demonstrar ao longo desta Análise que, no caso da telefonia, ambos os objetivos - universalização e competição - foram alcançados quase de maneira integral, embora de uma forma diferente do que fora planejado originalmente, em razão das rápidas e imprevisiveis transformações por que passou o setor em vinte anos". 
marco regulatório que buscassem, minimamente, refletir a nova realidade que se apresenta, dando continuidade ou até impulsionando o desenvolvimento do setor.

Contudo, passadas quase duas décadas do estabelecimento do marco regulatório, as regras de prestação dos serviços não se modificaram na medida necessária. O STFC continua sendo prestado no regime público pelas concessionárias, com obrigações de universalização, continuidade e controle tarifário, em que pese sua inserção em um mercado onde seu caráter de essencialidade esteja cada vez mais reduzido. A competência atribuída ao Poder Executivo em instituir ou eliminar, por meio de Decreto, a prestação de modalidade de serviço no regime público (art. 18, I da LGT) não foi exercida uma única vez neste período.

Além disso, outras obrigações que faziam sentido à época do estabelecimento do marco regulatório, mas não possuem qualquer tipo de utilidade atualmente, ainda são impostas às concessionárias do serviço, o que contribuiu para o descompasso entre as regras vigentes e a realidade do mercado de telecomunicações no país.

Tal realidade, acompanhada da crescente falta de atratividade de um serviço de telefonia fixo, da importância que assumiram serviços prestados em regime privado, com os quais o STFC compete, e da atual falta de sentido das assimetrias regulatórias estabelecidas na LGT, torna premente a necessidade de se rever de maneira profunda as atribuições de regime inicialmente estabelecidas, bem como as demais regras envolvidas na prestação dos serviços.

São demandadas alterações substanciais para desonerar, ou até mesmo extinguir, a prestação do STFC em regime público e trazer a regulação mais próxima à realidade do setor, uma vez que o modelo arquitetado em finais do século passado não mais se ajusta ao cenário atual.

Portanto, à semelhança do que ocorreu em meados dos anos 90 do século passado, quando se identificou que as normas existentes não mais se adequavam às demandas da sociedade, o momento atual exige mudanças de magnitude semelhante, a fim de se compatibilizar as regras aos diversos interesses envolvidos, sobretudo aqueles provenientes da sociedade. De acordo com o Professor Celso Antônio Bandeira de Mello (2010, p. 1067), "o mundo do direito não vive em suspensão alheio contexto socioeconômico que lhe serve de engaste", consequentemente, é preciso utilizar a matéria-prima oferecida pelas concepções atualmente dominantes com as regras que regem o setor de telecomunicações.

Em amplo processo de revisão, ainda não concluído, a Agência Nacional de Telecomunicações, o extinto Ministério das Comunicações, atualmente Ministério da Ciência, Tecnologia, Inovações e Comunicações, e o Poder Legislativo iniciaram debate baseado em resultados do Planejamento Estratégico da Agência, Relatórios de Consultorias internacionais contratadas pela União 
Internacional das Telecomunicações - UIT e Avaliação de Impacto Regulatório AIR feito pela Agência.

Como resultados diretos de tal debate, podem ser mencionados a Portaria $\mathrm{n}^{\mathrm{o}} 1.455$, de 8 de abril de 2016, do Ministério das Comunicações, que determina que seja buscada a simplificação do atual modelo de outorgas de serviços de telecomunicações, a desburocratização, dotando os procedimentos de licenciamento da maior celeridade; e o Programa Brasil Inteligente, aprovado pelo Decreto $\mathrm{n}^{\mathrm{o}}$ 8.776, de 11 de maio de 2016, do mesmo ente ministerial, que estabeleceu diretrizes específicas à Anatel no tratamento das concessões atualmente vigentes, de modo que se possibilite a migração das atuais concessões do STFC para serviços de maior liberdade, condicionando a migração ao atendimento de metas relativas ao provimento de serviços em banda larga.

De maneira semelhante, no âmbito do Poder Legislativo, deu-se início a esta discussão, por meio do Projeto de Lei $n^{\mathbf{0}} 3.453 / 2015$, da Câmara dos Deputados, disciplinando a migração dos regimes e o tratamento dos bens das concessionárias, gravados com o ônus da reversibilidade.

A compilação de tais informações está sendo realizada pela Agência em processo de revisão dos contratos de concessão e do Plano Geral de Metas de Universalização (PGMU), no exercício de sua competência estabelecida na Lei ${ }^{\circ}$ 9.472/97. Após o necessário exame da Agência, os detalhes da proposta de modificação ainda serão submetidos a Consulta Pública da sociedade e demandarão aprovação pelo Poder Executivo, por meio de novo Plano Geral de Outorgas, conforme estabelece o art. 18, II da Lei Geral de Telecomunicações. Contudo, a discussão dos conceitos, resultados e métodos de tratamento extrapola os objetivos do presente trabalho, até porque o debate ainda não se encerrou.

Além das questões relativas ao regime de prestação, matéria de abrangência geral e superior, outras discussões relacionadas a detalhes das regras aplicadas também se desenvolvem na Agência. A Agenda Regulatória do biênio 2015-2016, aprovada pela Portaria $n^{\circ}$ 1003, de 11 de dezembro de 2015, posteriormente modificada pela Portaria $n^{\circ} 750$, de 29 de junho de 2016, elenca as ações regulatórias prioritárias da Agência e estabelece as prioridades e prazos para os projetos de regulamentação.

Dentre as ações incluídas na agenda, destacam-se a própria revisão do modelo de prestação, brevemente mencionado anteriormente, mas também outras ações como a reavaliação do modelo de gestão de qualidade de serviços de telecomunicações e dos procedimentos de acompanhamento e controle das obrigações. Tais matérias possuam importância ímpar na regulação das telecomunicações, pois são elas que definem as regras finais aplicadas à prestação do serviço bem como a maneira de acompanhamento e controle da prestação dos serviços. 
Nas seções seguintes, serão avaliadas as aplicações dos conceitos de regulação responsiva nas ações regulatórias mencionadas acima, a fim de se identificar uma tendência da utilização da responsividade no desempenho das atividades pela Anatel. Em trabalhos anteriores, já foram identificadas algumas utilizações embrionárias destes conceitos pela Agência, na regulação da portabilidade numérica, das vendas no atacado e nos leilões de radiofrequência destinadas à tecnologia 4G (JESUS, 2015 e ARANHA, 2016).

\section{A revisão do modelo de gestão da qualidade dos serviços}

A prestação de serviços de qualidade é uma demanda constante da sociedade, sobretudo diante da importância e da constância que as telecomunicações tomaram no cotidiano das pessoas. As possibilidades que se abriram com o desenvolvimento da internet, permitindo a troca de informações em tempo real, inicialmente, fizeram que os microcomputadores, equipamentos que antes eram usados esporadicamente e somente para fins específicos, sobretudo profissionais, se tornassem praticamente onipresentes. Além disso, em um momento posterior, os chamados smartphones, que possibilitam acesso à internet e viabilizaram o desenvolvimento de inúmeras aplicações que, até pouco tempo atrás, eram inimagináveis, se tornaram companheiros inseparáveis de seus usuários. Estes dois fenômenos podem ser considerados como a face mais visível da revolução causada pelo franco desenvolvimento das telecomunicações, porém não são as únicas. Inúmeras outras aplicações, imperceptíveis aos olhos do grande público, são profundamente dependentes da troca de informações entre servidores espalhados por todos os cantos do mundo, seja no setor privado, como em bancos, ou no setor público, por exemplo, na apuração de impostos pela receita federal. $\mathrm{O}$ crescimento vertiginoso do intercâmbio de informações por redes de telecomunicações fez com que o tráfego de voz fosse superado pelo de dados, com tendência de se acentuar a distância nos anos vindouros com a evolução de novas tecnologias, tais como a Internet das Coisas (IoT), o que demonstra que tal caminho é sem volta.

Obviamente, a explosão do uso destes equipamentos foi acompanhada da exigência de que os serviços que suportam sua utilização fossem prestados com qualidade compatível à sua importância. A quantidade expressiva de usuários, o caráter pessoal e essencial que esses serviços tomaram acabaram reforçando a preocupação com a qualidade do serviço. É possível, inclusive, afirmar que, se no momento do estabelecimento do marco regulatório, os dois pilares do modelo eram a universalização e a competição, atualmente, a prestação de serviços de qualidade é a meta principal, aquela que exige maiores esforços do poder público 
e das empresas, para que se cumpra o estabelecido no art. $2^{\circ}$, III e no art. $3^{\circ}$, I da $\mathrm{LGT}^{15}$, in verbis:

Art. $2^{\circ} 0$ Poder Público tem o dever de: (...)

III - adotar medidas que promovam a competição e a diversidade dos serviços, incrementem sua oferta e propiciem padrões de qualidade compatíveis com a exigência dos usuários; (...)

Art. $3^{\circ} \mathrm{O}$ usuário de serviços de telecomunicações tem direito:

I - de acesso aos serviços de telecomunicações, com padrões de qualidade e regularidade adequados à sua natureza, em qualquer ponto do território nacional;

Tal realidade se reflete na estabilização e até no decréscimo da quantidade de usuários, seja de telefonia fixa, seja de telefonia móvel. De acordo com dados da Anatel, a quantidade de usuários de telefonia vem demonstrando um decréscimo acentuado, tendo registrado uma perda de cerca de mais de 24 milhões de usuários entre 2014 e $2015^{16}$. Embora tais números também tragam reflexos da crise econômica vivida pelo país nos últimos anos, há indícios de que o número total de usuários de telefonia tenha atingido o nível de saturação, e que aumentos, se ocorrerem, serão marginais.

Tal constatação talvez indique que todos os interessados em contratar serviços de telecomunicações já o possuem, cabendo às empresas agora, ao invés de buscar aumentar sua base a todo custo, por meio de promoções e reduções nos preços dos serviços, tentar melhorar a qualidade dos serviços prestados e, indiretamente, obter mais usuários e aumentar o seu faturamento.

O controle da qualidade dos serviços já vem sendo feito pela Agência praticamente desde sua criação, no final da década de 90 , em atendimento aos dispositivos da LGT supracitados. A obrigação de cumprimento de metas de qualidade já constava nos contratos de concessão firmados em 1998, tendo sido regulamentada pela Resolução no 30/98, que aprovou o Plano Geral de Metas de Qualidade para o STFC. Este instrumento foi desenvolvido com base nos aspectos mais relevantes à época, que abrangiam sobretudo aspectos técnico-operacionais da prestação do serviço, como taxa de completamento de chamadas ou a taxa de digitalização de rede, dentre outros.

Com o passar do tempo, estes instrumentos foram sendo remodelados para considerar aspectos adicionais aos já mencionados, tais como os indicadores de atendimento e de reação dos usuários ${ }^{17}$, e também para medir a qualidade de

${ }^{16}$ Fonte Anatel: Vide item nota 12 supra.

${ }^{17}$ Vide Regulamento de Gestão de Qualidade de Prestação do Serviço Telefônico Fixo Comutado, aprovado pela Resolução n ${ }^{\circ}$ 605/2012 e Regulamento de Gestão da Qualidade da Prestação do Serviço Móvel Pessoal, aprovado pela Resolução nº 575/2011. 
outros serviços criados posteriormente, como o Serviço de Comunicação Multimídia - SCM $^{18}$ ou os Serviços de Televisão por Assinatura ${ }^{19}$.

No modelo vigente, as prestadoras devem cumprir metas estabelecidas na regulamentação e, caso elas não sejam atingidas, instaura-se um Procedimento específico para apuração das irregularidades e, via de regra, são aplicadas sanções de multa pelos descumprimentos. Verifica-se, portanto, que as técnicas utilizadas são meramente punitivas, baseadas em estratégias de enforcement de dissuasão (deterrence), já descritas anteriormente neste trabalho.

Em que pese tenham sido feitas algumas adaptações, o foco dos indicadores se manteve nos aspectos operacionais originais, que consideram um rol exaustivo de parâmetros e que, muitas vezes, não refletem a real percepção da qualidade dos usuários do serviço. Ademais, a medida que regras mais detalhadas foram sendo estabelecidas, com a definição precisa de quais eventos incluir ou excluir do cálculo dos indicadores, mais energia foi sendo dispendida com tal controle por parte da Agência, ao mesmo tempo em que novos questionamentos na regulamentação foram sendo apontados pelas prestadoras. Deste modo, em diversas situações, a controvérsia final sobre um determinado indicador de qualidade terminava por se concentrar demasiadamente em um determinado aspecto que tinha pouco ou nenhum reflexo na percepção da qualidade de serviço pelos usuários, o que terminava prejudicando o atingimento do objetivo para o qual ele tinha sido criado $^{20}$. Como mencionado por Ayres e Braithwaite (1992, p. 26), regras essencialmente punitivas podem gerar um jogo de "gato-e-rato" que terão como resultado final um sistema de normatização por acréscimos que origina um grupo de regras incoerente e um legalismo sem sentido que se concentra em violações específicas, simples e visíveis e que negligenciam problemas sistêmicos.

Diante de tal realidade, a Agência iniciou discussão de um novo Modelo de Gestão da Qualidade que buscasse criar mecanismos para estimular a melhoria efetiva da qualidade do serviço, de modo que fosse totalmente compatível com as expectativas da sociedade e adaptável a eventuais mudanças ocorridas.

Uma das principais premissas que orientou o desenvolvimento do trabalho foi a unificação das regras de qualidade aplicáveis a todos os serviços, salvo quando existirem especificidades inerentes à natureza de cada um deles, como a mobilidade da telefonia móvel e o controle de velocidade de tráfego de dados do Serviço de Comunicação Multimídia. Além disso, buscou-se concentrar a análise em uma quantidade menor de indicadores estratégicos de maior sensibilidade aos

${ }^{18}$ Vide Regulamento de Gestão da Qualidade do Serviço de Comunicação Multmídia (RGQ-SCM), aprovado pela Resolução n ${ }^{\circ}$ 74/2011.

${ }^{19}$ Vide Plano Geral de Metas de Qualidade para os serviços de televisão por assinatura (PGMQ - televisão por assinatura), aprovado pela Resolução nº 411/05. 
consumidores, que seriam posteriormente examinados por meio de avaliação de satisfação e qualidade percebida.

Para o presente trabalho, a premissa que nos interessa diz respeito à utilização de estratégias características da Regulação Responsiva para o desenho regulatório, como expressamente mencionado pela área técnica da Agência responsável pela elaboração ${ }^{21}$, que propôs até a inclusão de um dispositivo na minuta proposta do Regulamento em elaboração, nos seguintes termos:

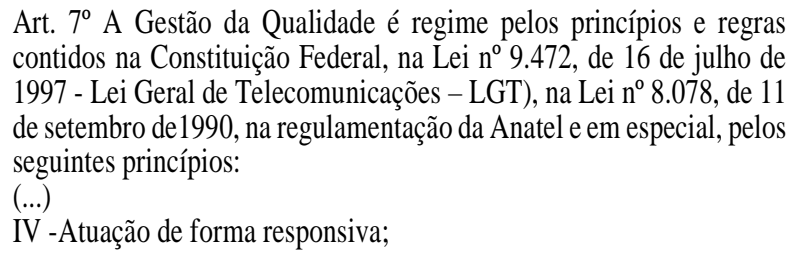

Pela proposta da área técnica, em um primeiro momento os resultados dos indicadores serão monitorados para se apurar o nível em que eles estarão, para somente a partir daí se estabelecerem as metas a serem cumpridas. Tal estratégia foi considerada necessária, pois os indicadores propostos são, em geral, inéditos e não seria possível definir, de antemão os níveis que deveriam ser atingidos pelas prestadoras. Corria-se o risco, como já ocorreu em versões anteriores do controle de qualidade, de serem fixadas metas extremamente restritivas, tornando impossível ou pouco provável seu atendimento, ou demasiadamente tênues, o que retiraria a necessidade de esforço das empresas para atingi-las. Tal período terá a duração de um semestre e os níveis serão definidos em quatro diferentes grupos de municípios, que levam em consideração o nível de competição neles existentes.

No período seguinte, no qual já se conhecerão as metas para cada grupo de municípios, os indicadores serão monitorados, durante o chamado "Ciclo de Avaliação", porém não serão adotadas medidas pela Agência caso se verifique que eles estão abaixo das metas desejadas. Neste momento, estão sendo utilizadas as técnicas regulatórias situadas na base da pirâmide de Braithwaite.

Ainda de acordo com a proposta da área técnica da Agência, ao final do período, caso se constate que os níveis realmente ficaram abaixo das metas previamente definidas, inicia-se o chamado "Período de Vigilância", ou seja, inicia-se a escalada da pirâmide. Durante tal período, que pode durar até 18 (dezoito) meses, serão tomadas medidas com crescente caráter intervencionista e punitivo, que seriam as camadas superiores da pirâmide regulatória. No primeiro semestre, os usuários das áreas onde foi constatada deterioração da qualidade

\footnotetext{
${ }^{21}$ Vide Informe $n^{\circ}$ 62/2016/SEI/PRRE/SPR, nos autos do Processo n ${ }^{\circ} 53500.006207 / 2015$ -
} 16, em trâmite na Anatel. 
deverão ser avisados pelas prestadoras do ocorrido e informados sobre as medidas que poderão ser tomadas caso a qualidade não volte ao patamar anterior. Além disso, a depender do nível de competição dos municípios, as prestadoras deverão realizar contrapropaganda ou então iniciar um processo de compensação de valores aos usuários localizados nestas regiões.

Caso as ações tomadas pela empresa não tenham o resultado desejado e a qualidade prossiga inferior aos níveis estabelecidos, a prestadora deverá, no semestre seguinte, compensar os usuários ali localizados em um patamar maior, desembolsando uma quantia superior por sua conduta inadequada.

No semestre subsequente, os níveis de qualidade serão novamente apurados e, se a qualidade ainda não estiver em níveis apropriados, poderá ocorrer a suspensão de vendas nos municípios onde há competição adequada ou o aumento do nível de compensação aos usuários, onde ela não esteja presente.

$\mathrm{Na}$ hipótese de as irregularidades permanecerem e a qualidade do serviço ainda não atingir os níveis adequados, serão instaurados processos regulares de apuração de descumprimento de obrigações, do qual poderão resultar sanções de multa. Além disso, o não atendimento dos requisitos mínimos de qualidade de um município possibilita a troca de operadora sem eventual exigência do pagamento de quebra de cláusula de fidelidade.

Em qualquer momento, durante o período de vigilância, o atingimento das metas implicará a suspensão do período de vigilância e o retorno ao Ciclo de Avaliação.

Fica evidente, portanto, a utilização de técnicas de Regulação Responsiva no presente caso. Iniciando-se na base da pirâmide, onde não existe qualquer ação regulatória, desde que os níveis estabelecidos sejam cumpridos, passa-se a níveis superiores de intervenção regulatória, até que se chega ao ápice da pirâmide, com a sanção de multa, em processo de apuração de descumprimento de obrigações ordinário. Em todas estas situações, é possível o retorno à base da pirâmide, desde que os indicadores atinjam os valores definidos anteriormente.

Em que pese a clareza na utilização destes conceitos, não houve a utilização de técnicas de melhoria contínua ou de recompensa nas situações em que os regulados atingiram resultados superiores às metas definidas. Conforme defendido por Kolieb (2015), somente parte do potencial das ações regulatórias estão sendo utilizadas neste caso.

\section{A revisão do modelo de acompanhamento e controle}

Como reguladora do setor de telecomunicações, a Anatel acompanha inúmeras obrigações estabelecidas em dispositivos legais, regulamentares e contratuais de todas as empresas atuantes no mercado. Além das questões 
relacionadas à qualidade do serviço prestado, tratadas na seção anterior, as regras vigentes envolvem aspectos que dizem respeito a universalização e massificação do acesso, a direitos e garantias dos usuários, a parâmetros técnicos e licenciamento de estações e equipamentos, a proteção à competição, dentre outros.

Dado o vasto rol e a complexidade das obrigações, a grande quantidade de regulados, a difusão dos serviços de telecomunicações por todos o país, e a escassez de recursos humanos, financeiros e tecnológicos da Agência, nem todas as obrigações podem ser permanentemente monitoradas e controladas da maneira como se espera. Além disso, a diferença de relevância entre as diferentes obrigações, que envolvem riscos e impactos inerentes a determinados descumprimentos, implica a necessidade de se planejar e priorizar as ações da Agência, a fim de se conceder tratamento prioritário aos temas mais relevantes, ao mesmo tempo em que se garante que os demais não sejam desconsiderados na atuação regulatória.

No âmbito do projeto de revisão dos procedimentos de acompanhamento e controle da Agência $^{22}$, ainda em andamento na Agência, buscou-se proporcionar a eficiência de atuação por meio da alocação de recursos e esforços onde eles são mais necessários, utilizando-se estratégias características de regulação responsiva.

Baseando-se em diretrizes da OCDE (2014), que trazem recomendações expressas para que o enforcement seja baseado em princípios de regulação responsiva (p. 33), a proposta da Agência envolve a definição de três níveis de atividades de fiscalização, a depender do grau de intervenção da Agência na atividade do fiscalizado. O primeiro envolve a atuação regulatória em escopo mais abrangente e possui foco na automatização de maior parte do processo. A depender dos resultados obtidos da atuação do primeiro nível, de acordo com a proposta em discussão, a intervenção poderá ser incrementada, com um aprofundamento da análise e a solicitação de dados adicionais para se apurar as irregularidades. Se após esta análise os resultados continuarem indicando descumprimentos, seriam tomadas ações específicas para a coleta de informações complementares, que poderiam envolver inspeções presenciais, a expedição de medidas cautelares ou a aplicação de multas.

Portanto, pela proposta em discussão, no primeiro nível, que pode ser considerado como a base da pirâmide, as atuações da Agência são principalmente baseadas no acompanhamento das informações prestadas pelos regulados e se baseia no cumprimento voluntário das obrigações.

\footnotetext{
${ }^{22}$ Vide Processo n ${ }^{\circ}$ 53500.205186/2015-10 da Anatel.
} 
No segundo nível, camada intermediária da pirâmide, as intervenções regulatórias se tornam mais incisivas e podem envolver direcionamentos e avisos aos entes envolvidos no acompanhamento.

Por fim, no terceiro e último nível, cume da pirâmide, o acompanhamento atinge seu ápice e o resultado pode ser a tomada de ações direcionadas, que podem envolver multas, cautelares e outras penalidades previstas na regulamentação.

A escalada da intervenção regulatória é muito clara na proposta da área técnica, a depender do comportamento do regulado e dos resultados coletados. A interação entre a Agência e as empresas vai determinar que tipo de ação regulatória que deve ser tomada, baseando-se no custo, no risco e no comportamento do regulado, o que reflete a responsividade da proposta em debate.

O nível do risco das condutas apuradas também será utilizado, o que termina por tornar o desenho proposto uma estratégia de regulação baseada em risco (BALDWIN et al., 2012. pp. 281-295).

Aqui cabe a mesma ressalva feita para o modelo de gestão da qualidade, no sentido de que não há qualquer proposta de técnicas de melhorias contínuas ou recompensas em situações de overcompliance.

\section{Conclusão}

A demanda crescente da sociedade pelo aprimoramento da atuação regulatória do Estado muitas vezes traz à tona questionamentos sobre o que seria exatamente uma melhor regulação, como ela pode ser atingida e como medir se ela é realmente melhor (BALDWIN, 2012). Diante da complexidade da matéria e das possíveis tensões e contradições envolvidas, tal resposta não pode ser facilmente obtida e requer análises e exames que superaram em muito o escopo do presente trabalho. Não obstante, existem estratégias regulatórias, baseadas em evidências teóricas e empíricas, que indicam caminhos a tomar e quais evitar.

A teoria da Regulação Responsiva, aqui tratada, pode ser considerada como uma dessas estratégias. Valendo-se de uma análise holística do setor regulado, na qual é concedida atenção especial ao mercado e ao comportamento dos agentes que nele atua, busca-se identificar os interesses envolvidos e as respostas possíveis para se impedir ou encorajar determinada conduta, a fim de se atingirem objetivos definidos pelo Estado. Muitas vezes, como demonstrado por Thornton, Kagan e Gunningham (2009) e sustentado por Ayres e Braithwaite (1992), o comportamento dos regulados não é direcionado somente por questões econômicas. Existem aspectos diversos da racionalidade puramente financeira que podem motivar condutas em determinada direção e desencorajar em outras. A Regulação Responsiva busca justamente encontrar tais motivações, revelandose uma estratégia interessante, na medida em que ela possibilita a aplicação da 
melhor alternativa de enforcement dentre as diversas disponíveis e utilizá-la de acordo com a especificidade da situação.

Obviamente, tal teoria está sujeita a críticas e elas existiram em abundância. Contudo, ao invés de diminuírem a importância de tal teoria, as fraquezas apontadas por diversos autores serviram para oxigenar o seu desenvolvimento e deram origem a diversas teorias alternativas, inclusive elaboradas por um de seus autores, que possuem como fundamento principal a pirâmide regulatória característica da teoria original.

Diante do potencial do uso da responsividade na atuação das agências reguladores no Brasil, observa-se o emprego de tais técnicas em alguns procedimentos já executados pela Anatel (ARANHA, 2016) e ANEEL ${ }^{23}$. Além disso, técnicas de regulação responsiva estão presentes de maneira expressa na discussão da evolução de itens de suma importância no novo modelo de prestação dos serviços no país: gestão da qualidade da prestação dos serviços de telecomunicações e acompanhamento e controle das obrigações pela Anatel, objeto de avaliação no presente trabalho.

Embora os instrumentos avaliados no presente artigo ainda estejam sujeitos a modificações, a simples presença de ferramentas características da regulação responsiva nas discussões da evolução do modelo regulatório brasileiro indica a busca pelo aprimoramento da atuação regulatória, por meio de técnicas mais avançadas que já estão sento utilizadas em outros países. É necessário continuar avançando, por meio do emprego de estratégias mais avançadas de responsividade, a fim de se extrair o máximo de tais regras e obter um real aprimoramento da atuação regulatória no país.

\section{Referência Bibliográficas}

ARANHA, Márcio Iorio. Telecommunications Regulatory Design in Brazil: Networking around State Capacity Deficits. Economia Pubblica, v. 27, p. 83-105, 2016.

AYRES, I., \& BRAITHWAITE, J. Responsive Regulation: Transcending the Deregulation Debate. Oxford: Oxford University Press, 1992.

BALDWIN, R. and BLACK, J. Really Responsive Regulation. LSE Law, Society and Economy Working Papers 15/2007 (disponível em: https://www.lse.ac.uk/collections/law/wps/WPS15-2007BlackandBaldwin.pdf).

${ }^{23}$ Vide Nota 4 supra. 
BALDWIN, Robert. Better Regulation: The Search and the Struggle. In: BALDWIN, R.; CAVE, M.; LODGE, M. (Eds.). The Oxford Handbook of Regulation. Oxford: Oxford University Press, 2010.

BALDWIN, R.; CAVE, M.; LODGE. Understanding Regulation. 2. Ed. Oxford: Oxford University Press, 2012.

BANDEIRA DE MELLO, Celso Antônio, Curso de Direito Administrativo, 27a Ed., São Paulo: Malheiros, 2010

BRAITHWAITE, J., MAKKAI, T., BRAITHWAITE, V. Regulating Aged Care: Ritualism and the New Pyramid. Chentelham, UK: Edward Elgar, 2007

BRAITHWAITE, John. The Essence of Responsive Regulation (Fasken Lecture): UBC Law Review, Vancouver, v.44, n. 3, p. 475-520. 2011.

GUNNINGHAM, N.; GRABOSKY, P. Smart Regulation: Design Environmental Policy, Oxford: Oxford University Press, 1998.

GUNNINGHAM, Neil. Enforcement and Compliance Strategies. In: BALDWIN, R.; CAVE, M.; LODGE, M. (Eds.). The Oxford Handbook of Regulation. Oxford: Oxford University Press, 2010.

JESUS, Carlos Moraes de. Teoria Responsiva na Regulação pela Anatel sobre o Serviço Móvel Pessoal 4G. Tese (Bacharel em Direito) - Faculdade de Direito. Universidade de Brasília, Brasília, 2015.

KOLIEB, Jonathan. When to Punish, When to Persuade, When to Reward: Strengthening Responsive Regulation with the Regulatory Diamond. Monash University Law Review 41(1), p. 136-162, 2015.

MARQUES NETO, Floriano de Azevedo. Regulação Estatal e Interesses Públicos. São Paulo: Atlas, 2002.

MARQUES NETO, Floriano de Azevedo; COSCIONE, Milene Louise Renée. Telecomunicações: doutrina, jurisprudência, legislação e regulação setorial. São Paulo: Saraiva, 2011.

MINISTÉRIO DAS COMUNICAÇÕES. E.M. n. 231/MC. Brasília. 1996

OCDE. Regulatory Enforcement and Inspections, OECD Best Practice Principles for Regulatory Policy, OECD Publishing, 2014

PARKER, C., Meta-Regulation: Legal Accountability for Corporate Social Responsibility? In: MACBARNET, D.; VOICULESCU, A.; CAMPBELL, T. The New Corporate Accountability: Corporate Social Responsibility and the Law. Cambrige: Cambridge University Press, 2007. 
PRESIDÊNCIA DA REPÚBLICA. Plano Diretor da Reforma do Aparelho do Estado. Brasília. 1995.

QUINALIA, Cristina Leão. Regime Público e Privado no Setor de Telecomunicações: análise de uma diferença e de uma semelhança. Revista de Direito, Estado e Telecomunicações, Brasília, v. 7, n. 1, p.73-116, maio, 2015.

SPARROW, M. The Regulatory Craft. Washington: Brookings Institution Press, 2000.

THORNTON, Dorothy, KAGAN, Robert A., \& GUNNINGHAM, Neil. When Social Norms and Pressures Are Not Enough: Environmental Performance in the Trucking Industry. Law \& Society Review 43(2): 405-435. (2009). 